\title{
Prevalence of Intestinal Parasite in Children and Their Mothers of a Slum in Dhaka City
}

\author{
Dr. Dorothy Shahnaz Mukul Fatema ${ }^{1 *}$, Prof. Dr. Be-Nazir Ahmed ${ }^{2}$, Dr. Abdul Khaleque ${ }^{3}$ \\ ${ }^{1}$ Department of Gynaecology and Obstetrics, Mymensingh Medical College, Bangladesh \\ ${ }^{2}$ Department of Parasitology, Institute of Epidemiology, Disease Control and Research (IEDCR), Mohakhali, Dhaka, Bangladesh \\ ${ }^{3}$ Department of Orthopaedics, Dhaka Medical College, Bangladesh
}

DOI: $10.36348 /$ sijog.2020.v03i03.009 $\quad$ | Received: 17.03.2020 | Accepted: 24.03.2020 | Published: 30.03 .2020

*Corresponding author: Dr. Dorothy Shahnaz Mukul Fatema

\section{Abstract}

Background: The Majority (65.3\% the respondents had been living in the 'Katcha' houses and none of them used to boil water, obtained from Water and Sewerage Authority (WASA) supply for drinking. Most (88.1\%) of the children defecated in the open field and almost all of the mothers (99.0\%) used to defecate in the hanging latrine. More than onefourth $(28.7 \%)$ of the children had no habit of handwashing after defecation and the majority $(69.3 \%)$ of the mother's used only water for washing hands after defecation. About one-third of the children (32.7\%) had complaints of diarrhea with abdominal pain in the last 3 months with $44.5 \%$ having a history of the expulsion of any type of worm with stool during that time. Objective: The objective of the study was to determine the proportion of under-five children with a parasitic infestation about their mother's infestation. Method: This descriptive study was conducted among mothers and their under-five children of Vashantek slum, Dhaka Cantonment, Dhaka from March 2003 to June 2003. Results: The prevalence of intestinal parasites was found to be $52.0 \%$ ( $48.5 \%$ in children and $55.4 \%$ in mothers). The prevalence of Protozoa was $13.2 \%$, for children $15.8 \%$ and $10.9 \%$ in mothers. Helminthes infestations were found among $39.6 \%$ of children and $54.5 \%$ mothers. Of the 56 mothers with intestinal parasitic infestations, $66.1 \%$ of their children showed positive results. The relative risk of parasitic infestation was 2.478 times higher among the children of the mothers having a parasitic infestation. Of the respondents, $39.6 \%$ children and $20.8 \%$ mothers had a history of taking antihelminthic drugs during the last six months. Conclusion: More than half of the study sample has intestinal parasitic infestation with a statistically significant relationship between the parasitic infestation of mothers and children.

Keywords: Parasitic, Helminthes, Infestation, Intestinal.

Copyright @ 2020: This is an open-access article distributed under the terms of the Creative Commons Attribution license which permits unrestricted use, distribution, and reproduction in any medium for non-commercial use (NonCommercial, or CC-BY-NC) provided the original author and source are credited.

\section{INTRODUCTION}

Intestinal parasitic infestation is an important public health problem in Bangladesh, especially for children. Poor housing conditions, unhealthy environment, lack of proper sanitation and other relevant conditions are well-known factors that contribute to the prevalence of parasitic infestation [1]. These infections result in considerable morbidity including growth retardation and anaemia in children, though they often go unnoticed [2]. The present work is an attempt to provide data on the trend and intensity of intestinal parasites infections at a slum Vashantek, Dhaka. The purpose of this study is to find the prevalence of intestinal parasite among fewer than five children and their mothers, the sociodemographic condition and knowledge in the personal hygiene of those mothers which affects their dependents.

\section{OBJECTIVE}

The objective of the study was to determine the proportion of under-five children with a parasitic infestation about their mother's infestation. 


\section{METHODOLOGY}

\begin{tabular}{|l|l|}
\hline Type of study & Cross-sectional study \\
\hline Place of study & Vashantek slum, Dhaka Cantt. Dhaka \\
\hline Study period & March 2003-June 2003 \\
\hline Study population & 5 children and their mothers of Vashantek slum. Dhaka. \\
\hline Sampling technique & Purposive \\
\hline Sampling size & 101 mother and 101 children \\
\hline Sampling unite & Stool sample of every mother and under-five child \\
\hline
\end{tabular}

Data collection tools: One structured Questionnaire and a checklist. One small clean, dry plastic container for a stool sample for each respondent. One microscope for stool examination. Normal saline, Lugol's Iodine Glass slides with a coverslip, wooden stick, marking pencil.

Data collection procedure: With the consent of the mother face to face interview was done by Questionnaire and a checklist. Stool samples were collected with clean dry small plastic containers, two of which were supplied to each mother by properly labeled with a serial number, name of the mother and child.

Stool Examination by Microscope: Only egg, Ova, cyst, and larva of the intestine parasite were identified. Results of the stool examination were collected by one of the authors and recorded in the data collection preforms.

Data Processing and Analysis: After compilation of data these were checked, verified edited and coded. Then the data were entered into the computer using the software program SPSS (Statistical Package for Social Science). Entered data were analyzed depending on the distribution of data.

\section{RESULTS}

The prevalence of intestinal parasites was found to be $52.0 \%$ among the respondents; $48.5 \%$ in children and $55.4 \%$ in mothers. See table 1 -

Table-1: Intestinal parasitic infestation of the mothers and their children

\begin{tabular}{|c|c|c|c|}
\hline Subjects & $\begin{array}{c}\text { A positive } \\
\text { number (\%) }\end{array}$ & $\begin{array}{c}\text { A negative } \\
\text { number }(\%)\end{array}$ & Total \\
\hline Children $(\mathrm{n}=101)$ & $49(48.5)$ & $52(51.5)$ & $101(100.0)$ \\
\hline Mothers $(\mathrm{n}=101)$ & $56(55.4)$ & $45(44.6)$ & $101(100.0)$ \\
\hline Total & $105(52.0)$ & $97(48.0)$ & $202(100.0)$ \\
\hline \multicolumn{4}{|c}{$\left[\mathrm{X}^{2}=0.97, \mathrm{df}=1, \mathrm{p}\right.$ value $\left.=0.324\right]$}
\end{tabular}

In table 2, a statistically significant relationship $(\mathrm{p}<0.001)$ was found between the infestation of mothers and their children.

Table-2: Relationship of intestinal parasitic infestation of children and their mothers

\begin{tabular}{|c|c|c|c|}
\hline \multirow{2}{*}{$\begin{array}{c}\text { Parasitic } \\
\text { infestation }\end{array}$} & \multicolumn{2}{|c|}{ Children $(\mathbf{n = 1 0 1})$} & Total \\
\cline { 2 - 3 } & Positive & Negative & \\
\hline Mothers & $37(66.1)$ & $19(33.9)$ & $56(100.0)$ \\
\cline { 2 - 3 }$=101$ & $12(26.7)$ & $33(73.3)$ & $45(100.0)$ \\
\hline Total & $49(48.5)$ & $52(51.5)$ & $101 .(100.0)$ \\
\hline
\end{tabular}

$\left[\mathrm{X}^{2}=15.510, \mathrm{df}=1, \mathrm{p}\right.$ value $=0.001 ;$ Relative risk $\left.=2.478,(95 \% \mathrm{CI}=1.474-4.166)\right]$

The prevalence of helminthes was $39.6 \%$ for children and $54.5 \%$ for mothers. 


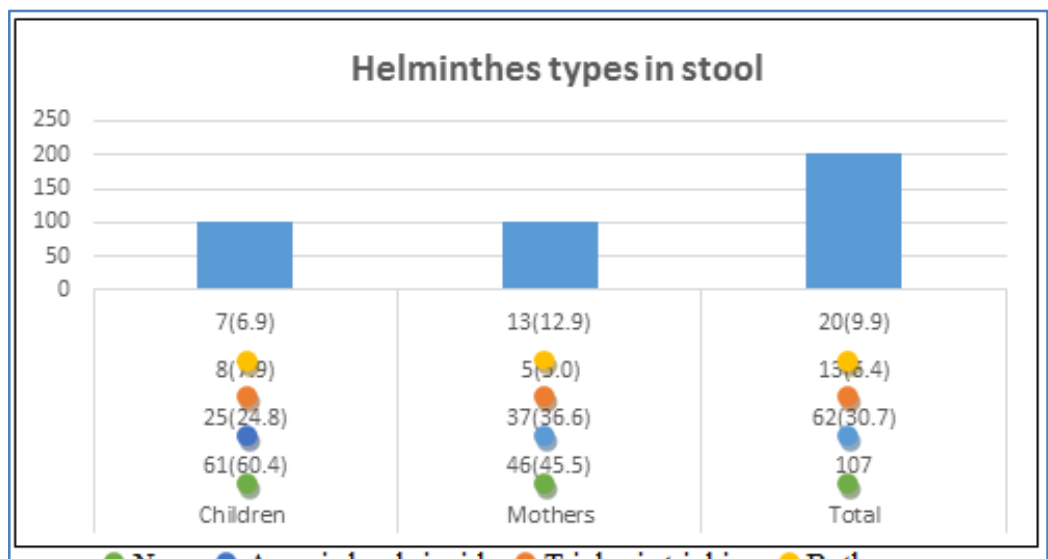

None Ascaris lumbricoides Trichuris trichiura Both

Fig-1: Prevalence of the type of helminthes (only ova)

The prevalence of protozoa was $15.8 \%$ for children and $10.9 \%$ for mothers. See table 3 -

Table-3: Prevalence of Protozoa

\begin{tabular}{|c|c|c|c|}
\hline Protozoa & Children & Mothers & Total \\
\hline None & $85(84.2)$ & $90(89.1)$ & $175(86.6)$ \\
\hline Entamoeba histolytica & $9(8.9)$ & $8(7.9)$ & $17(8.4)$ \\
\hline Entamoeba coli & $0(0.0)$ & $1(1.0)$ & $1(0.5)$ \\
\hline Giardia lamblia & $6(5.9)$ & $1(1.0)$ & $7(93.5)$ \\
\hline $\begin{array}{c}\text { Entamoeba histolytica plus } \\
\text { Giardia lamblia }\end{array}$ & $1(1.0)$ & $0(0.0)$ & $1(0.5)$ \\
\hline $\begin{array}{c}\text { Entamoeba histolytica plus } \\
\text { Entamoeba coli }\end{array}$ & $0(0.0)$ & $1(1.0)$ & $1(0.5)$ \\
\hline Total & $101(100.0)$ & $101(100.0)$ & $202(100)$ \\
\hline
\end{tabular}

\section{DISCUSSION}

Hassin during the year 1978 among 10629 number of stool specimens of the patients attending the outpatient Department of IPGM\&R and those hospitalized in different wards of the same institution for diseases other than helminthiasis, were examined. The overall prevalence was $30.76 \%$ [1]. These findings are much lower than the findings of the present study. It may be because the study was done on outpatient attending IPGM $\&$ R, where the patient came from different strata of socio-economic condition. Whereas the study samples were from a slum in the present study. So these findings do not support the present study. Nuruzzaman et al., worked from March 1967 to May 1969 on 1010 persons of all age groups in Mymensingh. The overall prevalence was 69.1\%. [2, 3] Martin et al. did the study in villages, Pullakandi, Noyagram and Noyapara of Jamalpur of north Bangladesh in March 1982 among 203 children. The overall parasitic infestation was $68 \%$ [4]. Huq et al., surveyed among 593 subjects of Dhaka City. The overall prevalence was $63 \%$ [5]. Masum et al. worked during the year 1987 in a village, Potazia, under Shahjadpur Upazila in the district of Sirajgang. A total of 257 fecal samples were examined. In this study, it was found that $81.32 \%$ of the population was infected with the parasite [6]. Hall et al. in his study, the overall parasitic prevalence was $92.6 \%$. Muttalib et al. [7] reported the overall parasitism was $99.03 \%$ and poly parasitism was $84.27 \%$
[8]. It was observed that among the 56 mothers with positive intestinal parasitic infestations, 37(66.1\%) of the children showed positive results for intestinal parasites, whereas $12(26.7 \%)$ showed positive results in mother having stool negative results and the results shows a statically significant relationship with maternal infestations with children infestations $(\mathrm{p}<0.001)$ and the chance of parasitic infestations 2.478 times higher among the children if the mothers having parasitic infestations (Table-2). Mothers transmit the infection to their children during the take care of them. There is again the possibility of transferring infection from children to mothers for intimate contact, i.e., the habit of mothers was eating children's leftover food. As children, mothers are also responsible for transmitting the infection to other family members. Children $84.2 \%$ had found no protozoa in stool, $8.9 \%$ Entamoeba histolytica, 5.9\% Giardia lamblia and 1.0\% Entamoeba histolytica and Giara lamblia, whereas among the mother $89.1 \%$ had no protozoal cyst, $7.9 \%$ had Entamoeba histolytica, 1.0\% had Entamoeba coli. (Table4). Haque et al., did the study on an urban slum Mirpur, Dhaka, Bangladesh. The age group of the children was 2-5 years. The prevalence of E histolytica infection was $4.7 \%$ [9]. The findings of this study are lower than the present study. Muttalib et al., worked on the villagers of Dhaka, Comilla, Barishal. The incidence was E. histolitica $40.88 \%$, E coli $1.38 \%$, G. lamblia $6.04 \%$ [8]. In this study, the prevalence of E histolitica is higher than the present study but the prevalence of G. lamblia 
supports the prevalence of the present study. Kuntz, reported the prevalence of $\mathrm{E}$ histolytica-37\%, Ecoli24.33\%, G lamblia-17\%[10]. Muttalib et al. [10] reported $21 \% \mathrm{G}$. lamblia in urban patients and $1.07 \%$ the new students of Dakha University who came mainly from villages. G. lamblia infection is low in rural Bangladesh but high in upper India and Dhaka city. ${ }^{8}$ These findings are greater than the finding of the present study. So these findings do not support the present study. Nuruzzaman et al. in Mymensingh, reported the prevalence was E histolitica $13 \%$, E coli $7.1 \%$, G. lamblia $12 \%$ [8]. This finding is almost similar to the finding of the present study. Children had of Ascaris lumbricoides 25(24.8\%), 8(7.9\%) Trichuris trichiura $8(7.9 \%)$ both Ascaris lumbricoides \& Trichuris trichiura 7(6.9\%). Among mothers, Ascaris lumbricoides 37(36.6\%), Trichuris trichiura 5(5.0\%) and both Ascaris lumbricoides \& Trichuris trichiura 13(12.9\%). (Table4) Kuntz. The persons harbored at least one species of parasites were average as follows: Ascaris lumbricoides $61 \%$, Trichuris trichiura 56\%, Hookworm $48 \%$, Enterobius vermiculaiis $3.3 \% .{ }^{9}$ Muttalib et al., (196) reported the infestation of Ascaris lumbricoides 40\%, Hookworm 8\%, and Trichuris trichiura $18 \%$ among the patients attending a private clinic in Dhaka [10]. Nuruzzaman et al., worked from March 1967 to May 1969 on 1010 persons of all age groups in Mymensingh. The prevalence of Ascaris lumbricoides 41\%, Hookworm 50\% [3] Hall et al., studied at a slum in Mirpur, Dhaka with 768 children. 634 children (82.6\%) were found to be infected with Ascaris lumbricoides and 711 (92.6\%) with Trchuris trichura. ${ }^{7}$ The findings of the present study are not consistent with the finding of these studies as a higher percentage of prevalence. These studies were done earlier times when it might be due to people were less aware of taking frequent anthelminthic drugs as it is nowadays. So the findings of the theses studies do not support the finding of the present study.

\section{CONCLUSION}

It is very difficult to draw any generalized conclusion from a study conducted with a limited number of respondents. Despite that, the researcher tried to obtain some factors regarding the prevalence of intestinal parasitic infestation. From this study, it can be concluded that overall parasitic infestation was more than half of the respondents with a significant association between the infestation of mothers and the infestation of their children. And among the study population, helminthic infestation was more than protozoal infection.

\section{RECOMMENDATIONS}

Based on the findings of the present study, the following recommendations are made for taking effective prevention and control measures against intestinal parasites among the under-five children and their mothers of Vashantek slum, Dhaka Cantt Dhaka.

- Health education regarding intestinal parasitosis should be imparted to the mothers and on personal hygiene, sanitation, mother-child transmission of intestinal parasites.

- Medical checkup and stool examinations of the under-five children and their mothers especially in the slum area should be carried out and treatment for those who are found to be suffering from intestinal parasitosis.

\section{REFERENCES}

1. Hassain, S.K.R. (1980). Incidence of Helminthiasis in Residence of Dhaka; A Preliminary communication. Bangladesh Medical Journal, 13(2): 14-17.

2. Rao, V. G., Yadav, R., Bhondeley, M. K., Das, S., Agrawal, M. C., \& Tiwary, R. S. (2002). Worm infestation and anaemia: a public health problem among tribal pre-school children of Madhya Pradesh. The Journal of communicable diseases, 34(2), 100-105.

3. Nuruzzaman, M., \& Huda, Q. (1974). Parasitic Infection in Gastro-Intestinal Tract Disorder. Bangladesh Medical Journal, 2(2): 67-71.

4. Martin, J., Keymer, A., Isherwood, R. J., \& Wainwright, S. M. (1983). The prevalence and intensity of Ascaris lumbricoides infections in Moslem children from northern Bangladesh. Transactions of the Royal Society of Tropical Medicine and Hygiene, 77(5), 702-706.

5. Huq, F., Yamin, M.(1985). Necator Americanus and Ankylostoma Duodenalae in Dhaka City. Bangladesh Med. Res. Counc. Bull, 11(2): 43-49.

6. Masum, A.E., Rahman, M.A., \& Jahan, Y.(1992). Prevalence of Ascariasis in Rural Bangladesh. JOPSOM J. of Preventive and Soc. Med, 2(1): 1316.

7. Hall, A., \& Nahar, Q.(1994). Albendazole and infections with Ascaris lumbricoides and Trichuris trichiura in Children $\mathrm{n}$ Bangladesh, Trans.of the Roy. Soc of Trop. Med.and Hyg, 88, 110-112.

8. Muttalib, M.A., Islam, N., \& Islam, S.(1976). Prevalence of intestinal Parasite in rural Children of Bangladesh. Bangladesh Medical Journal, 5(1): 9-27.

9. Haque, R., Ali, I.M., \& Petri, W.A. (1999). Prevalence and Immune Response to Entamoeba Histolytica Infection in Preschool Children in Bangladesh, Am. J. Tr. Med. Hyg. June, 60(6): 1031-1034.

10. Kuntz, R.E. (1960). Intestinal Protozoa and Helminths in School Children of Dacca East Pakistan (East Bengal), the Am J of Trop Med and Hyg, 9. 